\title{
Making Multidisciplinary Meetings Work
}

\author{
Kathleen C. Taylor \\ MRS President
}

The Materials Research Society through its meetings promotes multidisciplinary research and thereby distinguishes itself from the long-standing single-discipline technical societies. Making multidisciplinary meetings work is a continuing challenge to the meeting chairs and symposium organizers, who must look beyond the bounds of established areas of study to identify opportunities for scientific progress in materials research through the synthesis of disciplines, techniques, and scientific understanding. MRS symposia are orchestrated with this synthesis clearly in mind. A well-organized symposium can hasten scientific progress and influence the course of science for years to come through the effective transfer of knowledge and stimulation of thought among the participants. We see this process at work at MRS meetings.

MRS meeting organizers are told that MRS has few formal requirements for suitable symposium topics. A symposium should concentrate on new material, materials properties, preparation, and development, although attention to techniques, devices, and applications can be ancillary issues. A symposium should have an interdisciplinary treatment. A symposium should bring together people working on various aspects of a selected topic who might not otherwise communicate with each other.

Flexibility and responsiveness play a major role in the development of a successful meeting. While some symposia can be planned well in advance of the meeting, others fill a need for immediate dialogue in fast-moving areas which cannot be anticipated early in the planning process. The symposia on high-temperature superconductors at the 1987 Spring and Fall MRS Meetings are the result of requests from the membership and the immediate responsiveness of the meeting chairs, and they are implemented with enthusiasm by a flexible MRS headquarters staff, working within a system that has been nurtured on innovation.

The membership has an ongoing role in development of symposia. Symposium topics come to MRS as informal suggestions and also as formal proposals. Helping the MRS Program Committee fulfill their objectives of dynamic, timely program development should be viewed both as an opportunity for members to provide input as well as a responsibility for members to accept in developing their own society. Jim Roberto, vice-chair of the Program Com-

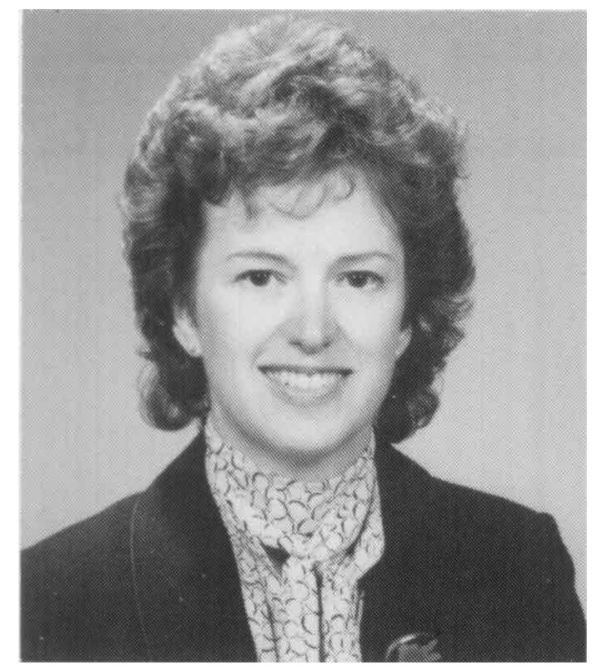

mittee, is chair of the subcommittee on program development. Tell him your ideas for future symposium topics.

Once a symposium topic is selected, the content of a symposium is determined by the participants who submit papers to the meeting as well as by the focus provided by the invited papers. You influence this process by your own contributions. We encourage you to influence the content of upcoming MRS symposia additionally by bringing appropriate symposia to the attention of your colleagues, who may not otherwise be aware of the meeting. Our diversity of symposium topics means we must work diligently to reach a new or expanding audience for part of each meeting. We further encourage you to make suggestions to the symposium organizers on how they can make their symposia truly interdisciplinary. Once you receive the Call for Papers booklet, contact the organizers of symposia which interest you and give them your suggestions for additional topics for discussion which you believe will add effectively to the treatment of the subject.

MRS draws on all scientific disciplines for both meeting and symposium organizers, and no one field of science is viewed as subsidiary to another. While some symposium organizers are well known within MRS, others come having never before attended an MRS meeting. MRS seeks all viewpoints in symposium organization and in symposium content. Our new symposium organizers bring fresh approaches to symposium planning. At the same time they recognize immediately how an MRS meeting can give attention to and help advance their own areas of research.

\section{Making multidisciplinary meetings work is a continuing challenge to the ... organizers, who must look beyond the bounds of established areas of study to identify opportunities for scientific progress....}

Putting together a successful MRS meeting is the result of a long hard effort on the part of the meeting chairs and symposium organizers. This effort is required because exactly what constitutes "materials research" today is not settled. The scope of materials research is neither arbitrarily defined nor static. It is, however, undergoing rapid evolution, a process catalyzed by meetings such as ours. Materials research draws on all scientific disciplines, so the need for programming for each MRS meeting must be examined broadly. Are we responding appropriately as a society to the growth of materials research? Should we create a definition for materials research and so limit our programming? Might materials research suffer if all who work on materials today define it, establish boundaries, and make it a discipline? Today the diversity and growth make us work hard and are, I believe, the reasons our meetings "work." Perhaps for now materials research should continue to resist strict definition. 


\section{When Your Research Is So Important, Why Compromise On Sample Preparation?}

South Bay Technology has been providing the materials research community with superior sample preparation equipment for over 22 years. By designing and manufacturing our own equipment, we have built a reputation for uncompromising quality, precision and service. By listening to your needs, we have been able to meet your requirements for design and performance-time and time again!

- Slicing Instruments

- Lapping \& Polishing Instruments

- Orientation Instruments

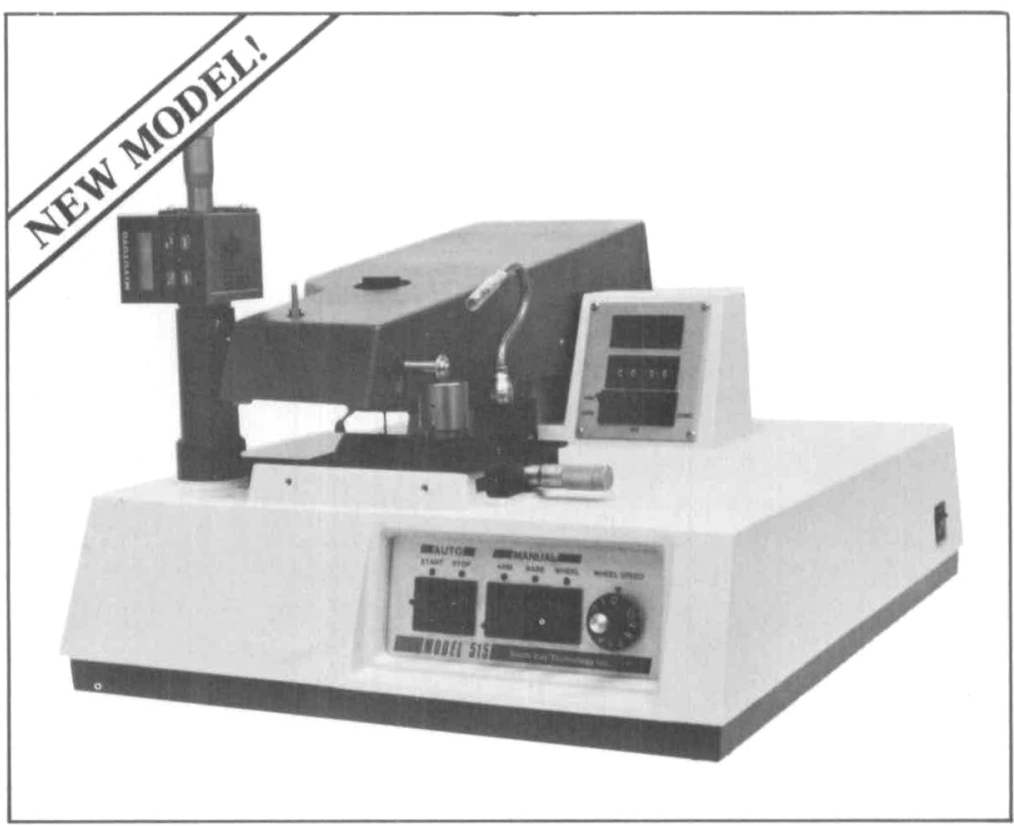

SBT MODEL 515 Precision Dimpling Instrument for TEM Specimen Preparation.

\section{WHY COMPROMISE?}

\section{SET \\ SOUTH BAY TECHNOLOGY \\ (818) $442-1839$ \\ TELEX: 311882 \\ - FAX: $818-442-8201$}

Australia/New Zealand

Imbros Pty. Ltd.

9 Warwick Street

G.P.O. Box 917

Hobart, Tasmania 7001

Phone: 34 9899/Telex: 58092

Fax: 344532

France

Cryophysics, SA

9, Rue Dallery

Jouy-En-Josas, F-78350, France

Phone: 39-56-00-66/Telex: 696096
Austria/West Germany

Cryophysics $\mathrm{GmbH}$

Landwehrstrasse 48

Darmstadt D-6100, West Germany

Phone: (06151) 86281/Telex: 419594

Fax: (6151) 84481

\section{Japan}

Meiwa Shoji Co., Ltd.

Tenshin Building

12-14, Kyomachibori 1-Chome

Nishi-Ku, Osaka 550 Japan

Phone: 06-448-3474/Telex: 64849

Fax: 816-447-0074
China

Global Technology

Xiyuan Hotel Room 919

Xijiao, Erligou

Beijing, China

Phone: 890721 Ext. 919

Telex: 22831

United Kingdom

Testbourne Ltd.

9 Sheppard Road

Basingstoke, Hampshire

RG21 3HT, England

Phone: (STD 0256) 467055

Telex: 858029 